\title{
Ecoturismo de base comunitária: uma realidade ou uma utopia
}

\author{
Raquel Fernandes de Macedo ${ }^{i}$ \\ Viviane Costa Fonseca de Almeida Medeirosi ${ }^{\mathrm{ii}}$ \\ Francisco Fransualdo de Azevedo ${ }^{\mathrm{iii}}$ \\ Maria Lucia Bastos Alves ${ }^{\text {iv }}$ \\ Universidade Federal do Rio Grande do Norte (Brasil)
}

\begin{abstract}
Resumo: O presente artigo trata de um ensaio teórico conceitual focalizado nas relações do ecoturismo com o processo de globalização e as contradições que envolvem crescimento econômico e o desenvolvimento. Nos procedimentos metodológicos levantou-se a seguinte hipótese: o ecoturismo de base comunitária é um aliado do processo de construção do desenvolvimento das populações autóctones. Para tanto, foram trabalhadas questões como o envolvimento da economia solidária, do turismo comunitário e do ecoturismo na perspectiva de colaborar com a inserção da comunidade local na atividade turística. Nesse contexto, esse trabalho aborda questões sobre o ecoturismo de base comunitária, questionando o imperativo do desenvolvimento na formação do bem estar dos seres humanos e observando também seus benefícios para a comunidade autóctone.
\end{abstract}

Palavras-chave: Desenvolvimento Local; Globalização; Turismo; Ecoturismo; Comunidade Autóctone.

Title: Community-based ecotourism: a reality or a utopia

\begin{abstract}
This paper is a theoretical essay focused on the conceptual relations of ecotourism in the process of globalization and the contradictions involving economic growth and development. In the methodological procedures rose the following hypothesis: community-based ecotourism is an ally of the construction of the development of local peoples. It had been worked on issues such as the involvement of social economy, community tourism and ecotourism in the prospect of collaborating with the insertion of the local community in tourism. In this context, this work addresses issues of community-based ecotourism, questioning the development imperative in the formation of well-being of humans and also noting its benefits to the local community
\end{abstract}

Keywords: Local Development; Globalization; Tourism; Ecotourism; Local Community.

i Mestranda em turismo. Bolsista Capes. Universidade Federal do Rio Grande do Norte. E-mail: raquelfmacedo@gmail.com

ii Mestranda em turismo. Bolsista Reuni. Universidade Federal do Rio Grande do Norte. E-mail: liramedeiros@ yahoo.com.br

iii Professor Adjunto da Universidade Federal do Rio Grande do Norte, Brasil. Doutorado em Geografia pela Universidade Federal de Uberlândia, Brasil (2007). E-mail: ffazevedo@gmail.com

iv Professor Adjunto I da Universidade Federal do Rio Grande do Norte, Brasil. Doutorado em Sociologia pela Universidade de São Paulo, Brasil (2004). E-mail: mluciabastos29@yahoo.com.br 


\section{Introdução}

O presente artigo propõe uma reflexão teóricoconceitual centrada nas relações e influências da globalização no processo de construção do desenvolvimento nos países periféricos, bem como, os conceitos que envolvem as diferenças entre desenvolvimento e crescimento econômico e as suas implicações na construção da atividade turística, em especial as centradas no turismo de massa ${ }^{1}$ que na grande maioria é representada pelo binômio sol e mar, e as suas conseqüências para a população autóctone. Neste contexto, dar-se-á ênfase ao desenvolvimento das atividades realizadas pelas comunidades locais ${ }^{2}$ na perspectiva de geração de melhorias socioeconômicas, com ênfase no ecoturismo de base local.

Nesse sentido, foi levantada a hipótese de que o ecoturismo de base comunitária é um aliado para o processo de construção do desenvolvimento da população autóctone. Sendo assim, o presente estudo teve como referência os estudos de Gallero (1996) no qual afirma que o turismo se sustenta sobre a diversidade das culturas e sobre as expressões da vida humana. Por isso, deve ser observado como um fenômeno social e não meramente como uma solução para a balança de pagamentos ou para a prosperidade das empresas, bem como, deve ser levado em consideração às atividades realizadas pelos autóctones e a utilização do meio ambiente natural a seu favor com o objetivo de desenvolver a atividade ecoturística, baseada nas premissas da sustentabilidade.

Dessa forma, observou-se que ao se tratar da construção do desenvolvimento se faz necessário que sejam trabalhadas questões que vão além do Produto Interno Bruto (PIB) e do Produto Nacional Bruto (PNB), uma vez que se não cairá no restrito argumento que associa crescimento de números como sendo diretamente proporcional à melhoria da qualidade de vida da população, o que não confere com o pensamento de diversos autores contemporâneos entre eles, $\mathrm{Sen}^{3}$ (2000) que centra o desenvolvimento em algo além dos números da balança comercial dos países. Para este referido estudioso o desenvolvimento humano está intimamente ligado à obtenção de liberdade, a saber: educação, saúde, moradia, lazer, cultura e direitos políticos; e a liberdades substantivas.

Face ao exposto, o artigo tenciona destacar a atividade do ecoturismo desenvolvida pelos autóctones, ou seja, atividade centrada nas características socioeconômicas das localidades como forma de inserção dos benefícios advindos da atividade em questão, bem como, proporcionar um desenvolvimento centrado na liberdade individual e coletiva das pessoas e no respeito aos recursos naturais existentes nas localidades, visto que os mesmos são limitados.

No que tange a ligação do ecoturismo e a economia popular solidária, pode-se notar que esta poderá trazer formas alternativas de inserção das comunidades que vivem no entorno das áreas naturais, pois ao longo dos últimos anos, o turismo tem se instalado em diversas áreas com o propósito de gerar melhorias relacionadas à geração de emprego e renda, principalmente; porém, não é esta a realidade que se encontra nos países periféricos, como é o caso do Brasil (Bursztyn, 2005).

Entretanto, esta realidade pode ser alterada por meio da inserção de produtos advindos da extração vegetal, como por exemplo, açaí, piaçava, juá, dentre outros produtos, produzidos por cooperativas e associações ligadas ao turismo, posto que as mesmas passem abastecer as empresas turísticas, tais como meios de hospedagens e restaurantes com cosméticos e alimentos. Além disso, pode ser elaborado um roteiro em meio ao processo de fabricação de tais produtos, como forma de atrair visitantes que se interesse por produtos naturais.

No Brasil, a atividade turística ao longo dos anos vem gerando um grande número de empregos informais como relata o Ministério do Turismo (MTUR2007) em estudos realizados para o Plano Nacional de Turismo 2007-2010 onde constataram que o montante de empregos informais correspondeu nos anos de 2003 $(3.449,174), 2004$ ( 3.651,052) , 2005 (3.827,872) já com relação aos empregos formais nestes mesmos períodos foram gerados 1.724,587, 1825,526 , 1.913 .936 o que comprova o afirmado acima quando o autor Bursztyn (2005) afirma que a atividade em questão não gera de fato os benefícios esperados.

Todavia, o ecoturismo, pode ser trabalhado de maneira integrada com a Economia Popular Solidária (EPS), para trazer resultados favoráveis no combate à pobreza e à exclusão social, pois a EPS mostra-se capaz de propor alternativas viáveis para a geração de emprego e renda, bem como para a conquista das necessidades básicas da sociedade ${ }^{4}$ atreladas uso dos recursos naturais de modo consciente. Estas conquistas podem vir através da sociedade organizada de novas formas de produção e reprodução dos seres sociais, de tal forma a reduzir as desigualdades, bem como a difundir os valores solidá$\operatorname{rios}^{5}$ (Mineiro, 2007).

\section{Turismo, globalização e desenvolvimento local}

O conceito de globalização não é uma terminologia nova, pelo menos em se tratando do capital. O que é novo é a simbiose do aspecto econômico com o político por meio da expansão do neoliberalismo (Tedesco; Cam- 
pos, 2001).

Este processo de globalização que é percebido nos dias atuais não é fato acabado, mas um processo em andamento, que começou a acentuar-se, a partir do século XX, com o processo de internacionalização do Estado provocado pela "desterritorialização do capital". As mutações no capitalismo vêm alterando suas formas, suas ideologias e criando sempre novas tensões e contradições, ou seja, se a prioridade do Estado no século XIX era o bem-estar da população, nas últimas décadas tem sido a de adaptar a economia nacional à economia mundial (Leal; Mingheli, 2001).

A abertura externa é uma das premissas da globalização, que trata da economia privada capitalista sob a ótica das empresas multinacionais e transnacionais em termos da competitividade que lhes é marca registrada (Aguiar, 2007).

Contudo o local e o global determinam-se às avessas, algumas vezes de modo equivalente e conseqüente, outras de modo desigual e desencontrado, mesclam-se e tencionam-se singularidades, particularidades e universalidades. A globalização pode ser compreendida como a intensificação das relações sociais em escala global, que unem localidades longínquas de tal forma que episódios locais são modelados por eventos, ocorrendo a muitas milhas de distância e vice-versa. Em conseqüência destas injunções impostas pelo processo de globalização, algumas nações sofrem com a obsolescência em várias esferas governamentais ou não e elas podem ser totais ou parciais. Por essa razão, o declínio do estadonação é um exemplo desta obsolescência, como realidade e conceito. Não se trata de dizer que deixará de existir, porém que está realmente em declínio, entra em um processo crítico, busca novos paradigmas. As forças sociais, econômicas, políticas, culturais, geopolíticas, religiosas e outras que operam em escala mundial desafiam o estado-nação, com a sua soberania, como o lugar da hegemonia.

Nesse sentido, Macleod (1999, p. 445) afirma que como a globalização pode ser descrita em termos de fluxo global, com a saída de habitantes de regiões que são agora parte fugas de tais pessoas terem acesso e experimentarem novas etnias, idéias e meios de comunicação. Nesse sentido, o turismo é o primeiro exemplo de um processo profundo de fluxo global: envolver pessoas que viajam para locais distantes, interagindo com culturas diferentes; utilizar as tecnologias do Oeste que abrangem o globo; apoiar e está apoiado por uma mídia e indústria de anúncios; facilitar as comunicações de idéias entre pessoas de culturas anteriores diferentes; e encorajar propagação de financiamento e mercado econômico para intensificar o consumismo dos produtos e serviços turísticos por parte dos visitantes.

Dessa forma, Doorne, Ateljevic e Bai (2003, p. 3) a economia contemporânea global tem se tornado característica para intensificação e sofisticação da cultura do consumo, e o turismo que também é uma atividade econômica providência uma oportunidade para afirmar um sentido de alteridade em si mesmo, ou seja, para um lugar em si mesmo distante dos outros ou para rearticular umas referências nostálgicas para perdida cultura através da modernidade.

Diante dessas buscas incessantes das pessoas por novos lugares, os governantes têm se utilizado disso para tentar promover o desenvolvimento em seus países, transformando-os em destinos turísticos, devido à crença de que irá gerar excessivos benefícios econômicos acarretados pelo turismo (Fernandes; Coelho, 2002 apud Dantas, 2005). Entre eles:

- Geração de emprego;

- Arrecadação de impostos;

- Geração de divisas;

- Redução de desequilíbrios regionais;

- Indução de investimentos;

- Multiplicação da produção.

Por essa razão, o turismo representa uma atração considerável a muitos governos do Terceiro Mundo, e dessa forma, ele tem sido amplamente promovido tanto dentro dos países periféricos quanto pelos "especialistas" do Primeiro Mundo como meio de diversificação econômica e como importante mecanismo para a obtenção de divisas estrangeiras (Mowforth; Munt, 2003).

A participação das nações periféricas na globalização se dá por meio do turismo. Todavia, pode-se perceber que os benefícios advindos da atividade turística para os países de Terceiro Mundo são insustentáveis, uma vez que o turismo praticado nos países periféricos, na sua grande maioria, é o turismo de massa, que gera poucos benefícios líquidos e não proporciona desenvolvimento para a população local. Dessa forma, corrompe as culturas locais e os benefícios econômicos potenciais são reduzidos como resultado da apropriação dos Países do Primeiro Mundo em grande parte do trade turístico mundial (Mowforth; Munt, 2003).

Sendo assim, é pertinente ressaltar também que a atividade turística antes de ser vista como "tabua de salvação" para os países em dificuldades econômicas, tem que ser analisado os verdadeiros benefícios e de fato para quem estes são gerados. Segundo, Rabahy (2003) e Mowforth e Munt (2003) turismo somente vem gerando de fato, contribuições para os países desenvolvidos, ou seja, para os países que já tem uma elevada receita e um elevado nível de renda e esta concentração está associada às condições socioeconômicas, ou seja, ao nível e 
distribuição de renda, ao tamanho da população às condições de acesso e proximidade do mercado consumidor.

Assim, faz-se necessário ressaltar o desenvolvimento endógeno do turismo. Não se pretende com isso, barrar completamente a entrada do capital internacional, mas procurar manter um desenvolvimento equilibrado e criar conexões (Organização Mundial do TurismoOMT, 2008) entre o mercado local e o internacional. Estas conexões podem vir através da economia solidária por meio das práticas coletivas, onde os membros comungam as expectativas de melhorias na qualidade de vida, autonomia e reconhecimento como ser humano, como ser social, através da colaboração e da vivência de princípios solidários nos grupos de produção, cooperada e/ou associada, das empresas autogestionárias (economia solidária), organizações populares rurais e urbanas (Alves, 2008).

Os grupos de economia solidária no turismo podem ser representados pela população local que desenvolve as suas atividades cotidianas, como pesca artesanal, artesanato, entre outros, de forma cooperada e ou associada. Para tanto, se faz necessário à inserção de seus produtos e/ou serviços no trade turístico ou diretamente aos turistas, por meio de feiras de negócios ou de exposições de artesanato.

Destarte, ao se analisar os efeitos da globalização, entre eles: desterritorização, desigualdade social, obsolescência governamentais, onde os governos assumem outros papéis com a crescente política neoliberal e as privatizações, trazendo como conseqüência a eximissão do estado de suas responsabilidades e obrigações para com a sociedade. Nesse sentido, o fazer local ganha espaço no cenário da governabilidade em sintonia com os interesses das comunidades, no que se refere à gestão municipal do destino, com isso difunde-se a gestão participativa territorial local que também é conhecida como gestão compartilhada (Rodrigues, 2002).

Compreende-se que a globalização traz de fato diversos efeitos negativos como os citados por Rodrigues (2002), mas pode também ser entendido como uma oportunidade do fazer local ter mais participação na gestão de seus direitos e deste modo alcançar o almejado desenvolvimento.

Para que se possa enfrentar a competitividade externa, faz-se necessário o fortalecimento da população local e, para tanto, se prima pelo desenvolvimento endógeno ou local, que pode ser compreendido como sendo um processo interno de ampliação continuada de agregação de valor na produção, bem como da capacidade de absorção da região (Martinelli; Joyal, 2004).

\section{A essência do desenvolvimento}

Os termos desenvolvimento e crescimento econômico de maneira geral são relacionados ao progresso das nações, porém não podem ser definidos como sendo sinônimos. Pensando nesta perspectiva, pode-se observar que o processo de crescimento trabalhado de forma isolada poderá trazer desequilíbrio estrutural para determinadas economias, e com isso gerar aos seus governantes e governados sérias dificuldades. Já o desenvolvimento, em grande parte dos casos, é capaz de gerar o crescimento econômico de um povo (Passos; Nogami, 1998).

O crescimento econômico pode ser caracterizado pelo aumento da capacidade produtiva de bens e serviços de uma economia, que tem como conseqüência o aumento do Produto Interno Bruto (PIB) tanto em termos globais quanto em termos per capita, fato este difere do processo de desenvolvimento, posto que esteja centrado não apenas nos fatores econômicos, mas também nos fatores sociais e políticos que envolvem uma sociedade (Passos; Nogami, 1998).

Autores como Singer (1999) também reforçam o pensamento de Passos e Nogami quando afirma que o crescimento econômico está centrado apenas em cifras, como o aumento do superávit primário, o aumento do PIB, a ampliação do consumo, a produção de bens e serviços e o aumento da renda per capita. Com isso, percebe-se que o crescimento econômico está pautado apenas em cifras e no aumento delas, não levando em consideração outras variáveis.

Em uma perspectiva mais ampla, pode-se dizer que o crescimento econômico é o aumento do Produto Nacional Bruto (PNB) e em sentido restrito, é o aumento do PNB per capita em um período de tempo (Singer, 1999).

Contudo, o crescimento econômico não se processa apenas pelo aumento das cifras do PNB ou do PIB (Produto Interno Bruto), como também pela:

- Melhoria da qualidade da mão-de-obra: que implica a melhoria dos níveis educacionais de treinamento e da capacidade dos indivíduos;

- Melhorias tecnológicas: eficiência na utilização do estoque de capital;

- Eficiência organizacional: maximização na utilização de recursos disponíveis (Passos; Nogami, 2003).

Indaga-se, então, se crescimento econômico sozinho será capaz de reduzir a pobreza e melhorar a qualidade de vida de uma população? Como também se este crescimento econômico apenas centrado no aumento do PNB ou do PIB pode ser sinônimo de desenvolvimento?

Em respostas a estas indagações, Sen (2000) afirma que: se o desenvolvimento estivesse ligado apenas a 
indicadores econômicos, não haveria a situação de nos Estados Unidos da América existir grupos substanciais de indivíduos, por exemplo, os afro-americanos, com níveis de renda e expectativas de vida iguais aos das populações dos países mais pobres do planeta, tais como a Sri Lanca, Jamaica e Costa Rica.

Dados do relatório do Desenvolvimento Humano em 1992, do programa das Nações Unidas para o Desenvolvimento, apresentam um quadro demonstrativo sobre a polarização social em crescimento. Este estudo revela que os $20 \%$ mais ricos da população mundial são donos de $82,6 \%$ do Produto Interno Bruto Mundial, de 94,6\% dos empréstimos comerciais, de $80,6 \%$ da popança interna e de $80,5 \%$ do investimento interno. Segundo este estudo, a probabilidade é que a desigualdade aumente. Ainda sobre este relatório, as distâncias entre os $20 \%$ mais ricos e os $20 \%$ mais pobres da população mundial duplicaram nos últimos 30 anos (Kliksberg, 1994).

Nessa perspectiva, destaca-se que no Brasil, nas décadas de 1960 a 1980, a taxa de crescimento da economia era de 7\% ao ano, e o país colocava-se entre as oito nações mais ricas do Ocidente. Esta perceptiva mudou, e em 2001 a nação brasileira se colocava como a $11^{\mathrm{a}}$ economia do mundo, porém, com relação ao IDH (Índice de Desenvolvimento Humano) em 2002 ela estava representada apenas na $73^{a}$ posição no ranking das nações mais desenvolvidas do mundo. (Rabahy, 2003) Por estas e outras razões, não se pode ver o crescimento econômico como fator sine qua non para o desenvolvimento de uma sociedade.

Desenvolver, portanto, não quer dizer simplesmente crescer ou regular a distribuição da riqueza, ele vai além do aumento e do crescimento numérico de valores econômicos, estando este pautado pelo desenvolvimento do ser humano (Rodrigues, 2002).

O processo de desenvolvimento será consolidado quando os indivíduos tiverem os seus direitos assegurados, sendo assim, a liberdade individual é fator sine qua non no combate aos problemas enfrentados pelo ser humano (Souza, 1999).

Nessa mesma perspectiva, Sen (2000) argumenta que o desenvolvimento é compreendido como um estado de liberdade, e que ela pode ser precursora de várias outras, entre elas o livre-arbítrio político, facilidades econômicas, oportunidades sociais, garantias de transparência e a segurança protetora. Estas liberdades poderão gerar, entre outros, o desenvolvimento econômico, que aumentará a renda e a riqueza de um país, desta forma refletindo no aumento do intitulamento ${ }^{7}$ econômico da população.

Destarte, não se pode pensar o processo de obtenção da liberdade como sendo apenas uma expansão econô- mica, tecnológica ou simplesmente modernização social (infra-estrutura urbana); tem que se trabalhar a liberdade também sob a ótica de outras vertentes, pois se sabe que o atual estilo de desenvolvimento, predominantemente de viés econômico, no qual, muitas vezes, as empresas e instituições trabalham concentrando-se apenas no lucro individual, tem se mostrado ultrapassado fato compreensível diante das inúmeras situações de desigualdades socioeconômicas enfrentadas pelas camadas mais desfavorecidas (Zechner et al., 2008).

Nessa perspectiva o estado de felicidade individual e ou coletiva, a não exclusão social a conservação ambiental, também podem ser compreendidos como desenvolvimento local (Souza, 1999).

Apoiado nestas premissas, o Butão, país fincado nas Cordilheiras do Himalaia, mede o estado de bem-estar de sua população não apenas pelo PIB, e sim pela Felicidade Interna Bruta (FIB). Este fato mostra que a preocupação desta nação não é apenas o crescimento numerário e sim o bem-estar de sua população. É por esse motivo que o economista Hirata (2005 apud Cozer, 2006: 83), especialista no papel da felicidade em políticas públicas, afirma que o "Butão devolve ao chão os pés da lógica ponta-cabeça do desenvolvimento".

De trocadilho hippie, "felicidade interna bruta" virou um parâmetro de verdade, tendo até sigla (FIB). "A filosofia da FIB é a convicção de que o objetivo da vida não pode ser limitado à produção e consumo seguidos de mais produção e mais consumo, de que as necessidades humanas são mais do que materiais."(Powdyel apud Cozer, 2006: 83).

Em síntese, o desenvolvimento deve ser visto como um processo de superação de problemas sociais, onde a sociedade se torna mais justa e legítima para os seus membros e desta maneira fazendo de seu povo mais feliz. Constata-se, com isso, que o crescimento econômico e o progresso tecnológico não são suficientes como parâmetros definitivos ou como sinônimos de desenvolvimento, pois este crescimento econômico pode se der à custa da degradação ambiental ou no progresso tecnológico que se faz em paralelo ao desemprego estrutural .

Os autores Sen (2000) e Aguiar (2007) afirmam que a base para um desenvolvimento justo é a obtenção de qualidade de vida, socialização do poder, distribuição de renda, democratização do acesso aos bens públicos, culturais, os benefícios da tecnologia, em suma, a obtenção de liberdades sociais, econômicas, políticas e civis.

\section{Ecoturismo de base local: na perspectiva de melho- na para as comunidades autóc tones}

O turismo vem ao longo dos tempos se mostrando um instrumento auxiliador no processo de desenvolvimento regional quando trabalhado sob a perspectiva da sustentabilidade, isto é, quanto aos pilares do planejamento, 
de tal forma que venha a proporcionar tanto aos turistas quanto aos autóctones de hoje (bem como das gerações futuras) a satisfação de suas necessidades. (Sampaio et al., 2008)

O desenvolvimento do turismo sustentável atende às necessidades dos turistas de hoje e das regiões receptoras, ao mesmo tempo em que protege e amplia as oportunidades para o futuro. É visto como um condutor ao gerenciamento de todos os recursos, de tal forma que as necessidades econômicas, sociais e estéticas possam ser satisfeitas sem desprezar a manutenção da integridade cultural, dos processos ecológicos essenciais, da diversidade biológica e dos sistemas que garantem a vida. (Organização Mundial do Turismo-OMT, 2003: 24).

Contudo, será que de fato o turismo alcançará a sustentabilidade em todos os seus segmentos? Será que os turistas de hoje quanto os de outrora terão as suas necessidades e anseios atendidos? Será que os autóctones ${ }^{9}$ terão seus direitos atendidos hoje e no futuro? Ou seja, será que o tripé da sustentabilidade ${ }^{10}$ será alcançado?

Segundo Rodrigues (2000) esta sustentabilidade inexiste, visto que, atividade turística tem como principal objeto de consumo deste, a paisagem/espaço/ território o que gera uma aparente sensação que não há destruição desses lugares, o que suscita uma inexistente sustentabilidade. Assim, pode-se perceber que as atividades que produzem território são em sua essência insustentável, pois toda produção envolve modificação e esta modificação provoca destruição, ou seja, produção destrutiva.

Entretanto, o ecoturismo vem como uma atividade que propõe algo diferente dessa insustentabilidade, posto que possa ser entendido como um segmento do turismo que utiliza, de maneira sustentável, o patrimônio natural e cultural, incentivando sua conservação e buscando a formação de uma consciência ambientalista por meio da interpretação do ambiente, promovendo o bem-estar das populações envolvidas (Western, 1995).

Nesse contexto, é permitido dizer que o ecoturismo provoca e satisfaz o desejo que o turista tem de estar em contato com a natureza, explorando o potencial turístico, de forma a visar à conservação e ao desenvolvimento, evitando o impacto negativo sobre: a ecologia, onde são verificadas quantas pessoas uma área pode comportar e a sua vulnerabilidade no que concernem as espécies e os habitats, os problemas de poluição, de descarga de lixo e de perturbação de processos ecológicos essenciais, provocados pelo turismo; a cultura, que é fundamental para a comunidade residente da localidade turística por trazer oportunidades à mesma, através da geração de empregos e renda, incluindo elementos culturais como apresentações, produção de artesanato, dentre outras coisas para atender ao visitante; e a estética, por valorizar a paisagem, suscitando expectativas dos clientes, atraídos pela beleza cênica do lugar (Western, 1995).

Desse modo, Endres (1998) assegura que as perspectivas essenciais para o ecoturismo são a difusão de uma conscientização ambientalista; a obrigatoriedade da presença do Estado no fomento de atividades sustentáveis para o desenvolvimento dessas regiões; e, conseqüentemente, o benefício econômico direto para as populações que habitam nessas áreas, mediante a sua participação na composição do planejamento das atividades econômicas em suas comunidades.

O planejamento das atividades deve a princípio envolver estudos interdisciplinares e projetos multi-locais como ocorre no Lago Saimaa na Finlândia que tem um potencial para o turismo eco-cultural e aplica ferramentas para o desenvolvimento. Assim, a Finlândia apresenta um planejamento sobre a sua atividade turística com 4 grupos focados que sustentam turismo, dois campos diários baseados na observação participante e 40 documentos suplementares, segundo apontou uma pesquisa realizada por Wallace e Russel (2004) com 32 turistas entrevistados.

Todavia, o controle do turismo no Lago Saimaa passa por alguns conflitos entre os empresários locais e os ecologistas que defendem a fauna selvagem, pois esse lago é um sistema glacial de inter-conectividade do caminho das águas, de espécies únicas, dotado de água doce que cortam lagos afora para o mar.

No que tange ao ecoturismo, Stronza (2001, p. 275) afirma que os críticos apontam que particularmente se não é monitorado e não regulamentado, pode degradar áreas naturais e causar perturbações tanto as pessoas quanto aos animais selvagens. Já outros também temem que a retórica do ecoturismo seja pretexto para os negócios como é de costume, pois os empreendimentos comerciais muitas vezes utilizam o ecoturismo para maximizar os lucros das agências de turismo e guias profissionais. Isso ocorre porque para obtenção de lucro inclui-se qualquer intenção de proteger a natureza ou melhorar a vida das populações locais.

Dessa forma, no meio dos debates sobre o bom e o mau ecoturismo, os temas de participação local e apropriação local da infra-estrutura turística têm assumido uma nova importância. Para efeito de esclarecimento, pode-se dizer que cada vez mais, as comunidades locais estão se unindo em parcerias com órgãos governamentais, organizações não-governamentais e empresas privadas de turismo para planejar estratégias de turismo e desenvolver novas atrações para os visitantes e o resul- 
tado disso foi que os anfitriões estão ganhando cada vez mais controle sobre como o turismo afeta suas comunidades (Stronza, 2001).

Vale salientar que há questionamentos se as comunidades locais recebem o máximo de benefícios da indústria do ecoturismo, posto que o risco do ecoturismo mostrará apenas um sucesso completo se as comunidades locais tiverem a mesma proporção de controle e repartir eqüitativamente os benefícios (Jones, 2005).

Em síntese, Carrier e Macleod (2005 p. 317) diz que a Sociedade Internacional de Ecoturismo coloca o ecoturismo mostrando: proteção e benefícios da conservação; benefícios, respeito e ajuda autorizada às comunidades locais e educação, bem como entretenimento aos turistas. Entretanto, nessas descrições de ecoturismo estão implícitos e explícitos, os contrastes favoráveis com o turismo regular, posto que o ecoturismo segundo o mesmo autor é na verdade uma revolução profunda, conceituando e mudando a indústria do turismo de massa. Mesmo tendo uma má expressão sobre esse contraste no ecoturismo que gira em torno da definição do ecoturismo, que é tão elástico que pode estar se fechando sem sentido, por a elasticidade está manifestada nas estimativas divergentes do ecoturismo como as diferenças entre elas que serão vistas como uma reflexão amplamente divergente nessas definições. Por outro lado, é uma tendência para contextualizar ecoturistas e ecoturismo no que pode ser denominada uma "ecoturista bolha".

Talvez, essa visão do ecoturismo seja devido à percepção do valor comercial desse tipo de turismo e pelas maiores facilidades turísticas aplicadas e rotuladas aos próprios turistas, como pacotes de operadoras de turismo que incluem atividades como mergulho e banho de sol em um parque próximo hotel turístico. Essa fluidez de definição na prática é aparentemente uma revisão da influência do ecoturismo pela União Internacional para Conservação da Natureza. Nesse sentido, surgiu um novo termo chamado "turista bolha" que são turistas regulares que são gerenciados e insulares a partir de partes importantes dos seus destinos. Assim, o ecoturista bolha focaliza atenção na interação entre ecoturistas e a natureza e a cultura em particular que eles estão visitando, que induz a ignorância do contexto do visitante (Carrier; Macleod, 2005).

Contudo, para evitar essa ignorância por parte do visitante, tem-se primeiramente que fazer com que a população local compreenda a importância desse meio ambiente natural e se envolva no contexto do desenvolvimento do ecoturismo, participando de forma comunitária para desenvolver práticas que não agridam seus modos de vida, adequando-as a uma nova realidade, de modo satisfatório, com vistas a manter e proporcionar o seu bem estar. Nesse sentido, pode-se depreender que é este bem estar que a atividade ecoturística demonstra estabelecer através de práticas que valorizem o meio ambiente, a biodiversidade e a cultura local, o modo de vida natural, as especificidades de trabalhos e formas de subsistência do povo do interior e das peculiaridades regionais (Endres, 1998).

Em comunidades locais como as do nordeste do Equador e oeste de Belize, as nações da América do Sul apresentam obstáculos e oportunidades para o desenvolvimento do turismo na mata atlântica, e buscam apoio de investimentos de capital privado, de forma a incluírem uma posição relativa ao turismo baseado na natureza, nas suas respectivas economias nacionais, relativo rendimento com baixa busca para gerar um potencial menor do desenvolvimento de alternativas a proteção sócio-ecológica, o nível concomitante de cada estado para proteção ecológica (manifestação no estado regulatório da estrutura para proteção ambiental e orientação com respeito à noção de desenvolvimento sustentável) e a capacidade da população da mata atlântica se mobilizar para apoiar as trajetórias do desenvolvimento sustentável (Gould, 1999).

Todavia, Gould (1999) assevera que nesses locais do nordeste do Equador e oeste de Belize existem algumas variáveis que afetam a população da mata atlântica, tais como o relativo poder político mobilizado localmente e o interesse do capital privado extra-local que surge do resultado da economia nacional do turismo de natureza.

No entanto, Ruiz Ballesteros et. al.(2008, p. 403) afirmam que o turismo no Equador o turismo em áreas naturais tem sido desenvolvido principalmente pelas comunidades indígenas que trouxeram a proposta do turismo comunitário, pois umas 60 comunidades indígenas e campesinas ofertam turismo comunitário, beneficiando diretamente e indiretamente cerca de umas 15.000 pessoas. Assim, por definição o turismo comunitário no Equador complementa o funcionamento econômico da comunidade.

Vale mencionar que o Equador apresenta uma atuação estratégica governamental que contribuiu para o desenvolvimento do primeiro Plano Estratégico de Turismo que se destaca por apoiar o turismo comunitário que envolve a presença dos indígenas (Ruiz Ballasteros; Hernández-Ramírez (2010).

Dessa maneira, pode-se perceber que o turismo comunitário tenta proporcionar o desenvolvimento das comunidades através de iniciativas que decorrem dos arranjos produtivos locais que trabalham na perspectiva de proporcionar desenvolvimento de forma cooperada e compartilhada (Sampaio et al., 2008), e desta for- 
ma tentar ao máximo alcançar sustentabilidade, visto que, através da inserção das comunidades no processo de planejamento, execução e gerenciamento da atividade em questão poderão ser minimizados o vazamento da receita turística e a melhoria da participação da população nos lucros advindos desta atividade.

Nesse contexto, pode-se afirmar que o turismo comunitário pode ser entendido como toda forma de organização com base na especialidade e na auto-gestão dos recursos pertencentes à comunidade. Trata-se de práticas solidárias e democráticas de trabalho e na distribuição de forma igualitária das riquezas geradas pelo desenvolvimento da atividade. É um turismo baseado na interação entre a comunidade e o turista, cuja motivação está centrada nas peculiaridades da comunidade, entre elas: os valores, hábitos e tradições locais. (Ramos, 2008)

Para Coriolano (2003), o turismo comunitário pode ser entendido como aquele em que as comunidades de forma cooperada ou associada detêm o controle efetivo das atividades econômicas de maneira associada à atividade turística. Este controle está centrado desde o planejamento até ao desenvolvimento e à gestão das atividades para que desta forma venham a proporcionar a melhoria da qualidade de vida.

Portanto, o turismo comunitário é realizado de forma integrada às demais atividades econômicas desenvolvidas pela comunidade, gerando iniciativas que valorizem e fortifiquem a agricultura, a pesca artesanal e o artesanato (Freire, 2007 apud Coriolano, 2003).

Em outra abordagem o Turismo Comunitário pode ser entendido como um segmento de turismo onde existe a preocupação com a preservação e valorização do ambiente natural e cultural e a participação das comunidades nas tomadas de decisão na administração e gestão da atividade, bem como através dos seus benefícios (Freire, 2007 apud Coriolano, 2003).

Para que o turismo comunitário se desenvolva de maneira satisfatória, faz-se necessário desenvolvê-lo dentro dos pilares da sustentabilidade, pois da forma que o turismo vem se desenvolvendo, pouco tem contribuído para o processo de inclusão das comunidades locais, o que causa, além disso, perda considerável da identidade cultural destes autóctones (Bursztyn, 2005).

Os impactos gerados pela atividade turística fazem com que muitos a vejam como uma das principais atividades do mundo. Nos últimos anos, entretanto, cada vez mais pessoas têm encarado o turismo como um instrumento a serviço da globalização - entendida por sua vez, segundo Mowforth e Munt (2003), como um processo de expansão global do capitalismo ocidental - e, como tal, uma ameaça aos costumes e à economia local. Por conseguinte, têm proliferado as formas de organização e resistência a esta forma de "neocolonialismo", que invade terras, subestima culturas e ameaça o litoral.

De acordo com Barbosa et al. (2008), muitas comunidades litorâneas brasileiras sofrem com os impactos da atividade turística. Muitas colônias pesqueiras tornaram-se relevantes núcleos receptores de turistas, nacionais e internacionais, e acabaram perdendo as suas características e seus espaços para dar lugar a um turismo excludente, pois na grande maioria das vezes a população local fica à margem dos ganhos e benefícios gerados pelo turismo globalizado ou de massa.

Por esse motivo, há comunidades tradicionais que impedem o avanço deste tipo de turismo predador e organizam em seus territórios políticas alternativas de forma planejada, integrada e organizada, com base no trabalho comunitário e participativo.

Desse modo, a comunidade autóctone encontra formas de trabalhar o local, a história, a cultura, o meio natural e os produtos derivados da economia tradicional e local, de maneira tal a transformá-los em atrativos turísticos naturais e culturais (Souza Neto et al., 2008).

Para Coriolano (2006), a atividade turística não pode ser julgada como totalmente boa ou totalmente má, como pensam os grupos radicais, trata-se de um serviço que só pode ser usufruído por aqueles que têm poder aquisitivo suficiente, mas pode ser comercializado por varias indivíduos. Desta forma, poderá gerar benefícios a um grande número de pessoas e proporcionar melhores condições àqueles que vêem no turismo uma oportunidade de trabalho.

As atividades turísticas desenvolvidas com base local têm características harmônicas, que estão fundamentadas na autodeterminação, na valorização da população nativa e no respeito ao meio ambiente. Esta denominação de turismo de base local não difere dos conceitos de turismo comunitário, pois ambas tratam do desenrolar da atividade turística no seio da comunidade e na sua valorização.

Com base no exposto por Aguiar (2007), pode-se perceber que o turismo de base local ou comunitário está fundamentado no ser social e nas suas características sociais, culturais e no meio que as circundam. Percebese também que este segmento do turismo está centrado nos três eixos da sustentabilidade, a saber, o social, o econômico e o ambiental, de maneira a proporcionar equidade social.

Ademais, Heuman (2005) ressalta que é importante observar também as relações entre população local e turistas, posto que além dos eixos de sustentabilidade ora citados tem-se que levar em consideração os elementos da hospitalidade tradicional, tais como: 
- Proteção dos turistas pela população local que é uma forte ameaça a cultura tradicional da hospitalidade, uma vez que antigamente os visitados providenciavam alojamento, alimento e segurança para proteger o visitante pelo fato dos visitados gostarem de receber, mas hoje em dia a hospitalidade é comercial, visto que não se oferece alimento, alojamento ou segurança se não for de acordo com um contrato.

- Reciprocidade que é freqüentemente uma norma de hospitalidade ocorre em muitos lugares do mundo como, por exemplo, no Nordeste da Tailândia e no Iran são distribuídos presentes aos turistas como um convite ao seu retorno.

Assim, para que ocorra a hospitalidade dos visitantes para com os visitados é relevante notar que os visitados que são os anfitriões devem se inserir na atividade turística, não somente quanto a questões de oferecer alimentação, alojamento e segurança, como também informações sobre o destino, por essa razão é necessário o envolvimento da comunidade como um todo, pois segundo Pearce (2000), o desenvolvimento das comunidades do entorno dos centros turistificados só realizar-se-á mediante a participação das comunidades nas informações passadas aos turistas e no processo de planejamento, execução e monitoramento das políticas governamentais que são tencionadas para o turismo. O que difere do pensamento de outros autores como o que segui, visto que arrazoa.

Para Martinelli e Joyal (2004), o desenvolvimento local pode ser estudado por diferentes olhares, e por essa razão eles afirmam que muitos podem vê-lo sob o prisma do desenvolvimento econômico, voltado para os aspectos competitivos; bem como na visão dos governantes e das pessoas, ao pensar em promover o desenvolvimento das regiões e das comunidades, voltando-se apenas para os aspectos econômicos, levando em consideração apenas questões financeiras, tributárias e de geração de receitas. O processo de desenvolvimento local pode ser também compreendido como sendo aquele que ocorre de baixo para cima, ou seja, tendo início das potencialidades socioeconômicas originárias do próprio local, ao invés de um modelo imposto de desenvolvimento que parte de cima para baixo.

Observa-se, com isto, que para que se tenha desenvolvimento, faz-se necessária a participação da população local nas atividades sociais e econômicas, além da participação política, visto que ele e necessária para que as tomadas de decisões governamentais sejam centradas nas necessidades da população, para que desta maneira os benefícios sejam de fato geradas para todos os atores locais.

Também se pode compreender desenvolvimento local como sendo o reforço das comunidades onde são dinamizadas as suas potencialidades, porém sendo necessária a reunião de diversos fatores, entre eles o grau de educação da população, para que se tenham pessoas com condições de tomar iniciativas, assumir responsabilidades e empreender novos negócios (Martinelli; Joyal, 2004).

Nessa perspectiva, o processo de desenvolvimento está centrado no ser humano e na construção de sua liberdade, ou seja, na construção e formação do ser com seus direitos e deveres assegurados pela nação, como Sen (2000) coloca, a seguridade protetora, o direito ao voto, a saúde, a educação, a moradia e todos os direitos básicos aos quais os seres humanos têm assegurado através dos direitos universais humano.

Sendo assim, não basta dar proventos aos referidos seres, se faz necessário algo a mais, é preciso os prover de conhecimento para que desta forma ele seja capaz de caminhar sozinho e alcançar o seu desenvolvimento como liberdade.

Por essa razão, Coelho (2001 apud Martinelli; Joyal, 2004) afirma que o desenvolvimento econômico local pode ser visto como aquele que constrói um ambiente produtivo inovador, no qual se desenvolvem e se institucionalizam formas de cooperação e integração das cadeias produtivas e das redes econômicas e sócias, de tal modo que elas ampliem as oportunidades locais, gerem trabalho e renda, atraiam novos negócios e criem condições para um desenvolvimento humano e sustentável.

Com vistas no exposto acima, retoma-se a discussão que permeia o desenvolvimento local e as suas premissas. Para tanto, os aspectos econômicos não podem ser deixados de lado, porém, no ponto de vista da promoção da cidadania, só é aceitável como desenvolvimento o processo que coloca o ser humano e os interesses coletivos como ponto central de todo este processo de construção do desenvolvimento (Aguiar, 2007).

\section{Conclusão}

Diante do exposto, depreende-se que a globalização é um processo que traz somente benefícios para os países primeiro mundo, visto que, os países periféricos têm sua participação nesse processo por meio do turismo, porém perceber que os benefícios advindos da atividade turística aos referidos países são restritos, pois o turismo praticado, nessas nações, em suma, é um turismo massivo, que gera poucos benefícios líquidos em decorrência do vazamento da receita o que não proporciona desenvolvimento para a população local.

Sendo assim, é pertinente ressaltar que a atividade turística, bem como, o ecoturismo antes de ser vista 
como tábua de salvação para os países em dificuldades econômicas, como também como áreas em processo de devastação, tem que ser analisado sobre a óptica de, para quem são gerados os verdadeiros benefícios e como são utilizados recursos naturais do destino. Segundo Rabahy (2003) a atividade em questão só vem gerando de fato, contribuições para os países desenvolvidos, ou seja, para os países que já tem uma elevada receita e um elevado nível de renda e já tiveram grande parte das suas áreas verdes desmatadas. Esta concentração está associada às condições socioeconômicas e as condições ambientais, ou seja, ao nível e distribuição de renda, ao tamanho da população às condições de acesso, proximidade do mercado consumidor e quantidade de fauna e flora existentes.

Contudo, vale ressaltar que mais de $50 \%$ dos turistas emissivo internacional são formados por alguns países de maior prestigio político, econômico e social do mundo entre eles: Estados Unidos, Alemanha, Japão, Reino Unido, França e Itália. Do mesmo modo que no emissivo, constata-se excessiva concentração de fluxo quanto aos destinos turísticos, tanto em números, quanto em valores dos gastos. Ainda segundo este estudo o turismo é responsável por $1,42 \%$ do PIB mundial, proporção variável em função das características de cada uma das economias. Com relação ao turismo receptivo observa-se também que ele e tão, concentrado em poucos países, quanto o emissivo. Estes países são Maldivas, Antilhas, Ilhas Virgens, Bahamas, Babados. Estas localidades caracterizam-se por apresentar baixo nível de renda e têm na atividade turística a sua principal fonte de receita. Em conseqüência do relevante significado do turismo para as economias de localidades menos desenvolvidas, surge a tentação de se considerar esta atividade como um importante instrumento de redistribuição de renda.

Portanto constata-se que o processo de globalização, bem como a atividade turística de fato só contribui para proporcionar o firmamento dos países desenvolvidos no que se refere aos aspectos socioeconômicos e que as nações periféricas pouco recebem contribuições que de fato agreguem valores na formação de uma sociedade mais justa e livre.

Diante do que foi discutido também se constatou que o processo de desenvolvimento é inversamente proporcional à construção do crescimento econômico e que este é compreendido por muitos como sendo sinônimos, porém o procedimento de aumento das divisas está fortemente ligado aos números do PIB e do PNB, estes não são suficientes na edificação do desenvolvimento de povos e nações. A construção do desenvolvimento vai mais além dos números, ele é representado não apenas pelo Índice de Desenvolvimento Humano (IDH), mas seguin- do o pensamento de Sen (2000) este Desenvolvimento está centrado nas liberdades individuais e coletivas do ser humano. Também são demonstráveis por meio dos níveis de expectativa de vida, mortalidades infantis e Coeficiente de Gini (CG) (Dantas, 2005: 64).

Assim, mediante a todos os argumentos pode-se aprontar que o ecoturismo de base local ainda é uma utopia, visto que a atividade turística trabalhada nos países periféricos é desenvolvida pelas grandes corporações e que não vem ao longo dos tempos proporcionando as comunidades locais o verdadeiro intitulamento social e econômico o que não contribui de fato para a construção do desenvolvimento como liberdade.

Todavia, utopias são necessárias para que além de se imaginar lugares e pessoas melhores possam ser realizadas melhorias para todos que estão envolvidos na construção destes espaços. Sendo assim, o turismo de base local juntamente com o ecoturismo tem que ser trabalhado e desenvolvido em sintonia com as demais atividades para que possam contribuir tanto para a geração de emprego e renda quanto para as melhorias sociais, políticas, econômicas e ambientais dos respectivos países.

\section{Referências}

Alves, Flávia Keller; Falk, Vanessa Cristina Venzke; Sampaio, Carlos Alberto Cioce.

2008 "Arranjo socioprodutivo de base comunitária: interconectando o turismo comunitário com redes de comércio justo". Disponível em: <http://www. sits2008.org.br/oktiva.net/1893/secao/16333>. Acesso: 18 abr. 2008.

Aguiar, Geraldo Medeiros.

2007. Turismo, desenvolvimento local e integração regional. In: Seabra, Giovanni. (org) "Turismo de base local: Identidade Cultural e desenvolvimento regional". João Pessoa: Editora Universitária, UFPB, 2007.

Bursztyn, Ivan.

2005." Políticas públicas de turismo visando à inclusão social". Dissertação de Mestrado, UFRJ. Disponível em: <http://www.sits2008.org.br/oktiva.net/1893/secao/16333>. Acesso: 18 abr. 2008.

Carrier, James \& MacLeod, Donald

2005 "Bursting the bubble: the socio-cultural context of ecotourism" Journal of the Royal Anthropological Institute 11: 315: 334.

Corialano, Luiza Neide.

2008 "Turismo comunitário e economia solidária no Ceará". Disponível em: <http://www.sits2008.org.br/ oktiva.net/1893/secao/16333>. Acesso: 18 abr. 2008. 
Cozer, Raquel

2008 "Sorria você esta no Butão". Disponível em: <http://super.abril.com.br/superarquivo/2006/conteudo_450887.shtml>. Acesso: 12 jun. 2008

Dantas, Andréa Virgínia Sousa.

2005 "Uma análise sobre a relação turismo e pobreza no Rio Grande do Norte”. Natal, 161 f. Monografia (Graduação em Turismo) - Departamento de Ciências Administrativas, Universidade Federal do Rio Grande do Norte.

Doorne, S., Ateljevic, I. \& Bai, Z.

2003 "Representing identities through tourism: encounters of ethnic minorities in Dali, Yunnan providence, People's Republic of China", International Journal of Tourism Research 5, 1-11.

Endres, Ana Valéria

1998 "Sustentabilidade e ecoturismo: conflitos e soluções a caminho do desenvolvimento". Revista Turismo em Análise, vol. 9, n.1, maio de 1998.

Gallero, Lopes.

1996. El Impacto de la Globalizacion Sobre el Turismo. In: Rodrigues, Adyr A. B.(org) "Turismo e geografia: reflexões teóricas e enfoques regionais". São Paulo: Hucitec.

Gould, Kenned

1999 "Tactical tourism: a comparative analysis of rainforest development in Ecuador and Belize" Organization \& Environment 12 (3): 245: 262.

Heuman, Daniel

2005 "Hospitality and reciprocity: working tourists in Dominica" Annals of Tourism Research 12 (2): 407 418.

Ianni, Octavio.

1994 "Globalização: novo paradigma das ciências sociais". Estudos avançados, v.8, n.21. São Paulo, maio/ ago. Disponível em:

< http://www.scielo.br/scielo.php?script=sci_arttext\&p id=S0103-40141994000200009> Acesso em: 23 jun. 2009.

Jones, Samantha.

2005 "Community-based ecotourism: the significance of social capital." Annals of Tourism Research, Vol.32, No 2: 303-324.

Kliksberg, Bernardo.

1994 "Pobreza: uma questão inevitável". Brasília: ENAP.

Macleod, Donald

1999 "Tourism and globalization of a Canary Island" Journal of the Royal Anthropology Institute 5: 44356.

Martinelli, Dantas Pinheiro; Joyal, André.

2004 "Desenvolvimento local e o papel das pequenas e médias empresas". Baurueri, SP: Manole.

Mineiro, Fernando.

2007 "Economia solidária”. Assembléia Legislativa, Natal, RN.

MTUR - Ministério do Turismo.

2009 "Portal brasileiro do turismo". Disponível em: < http://www.turismo.gov.br/portalmtur/opencms/institucional/noticias/arquivos/cooperativismo_popular_promove_inclusao_social_em_regioes_turisticas. htm>. Acesso: 25 Jul. 2009

Mowforth, Martin; Munt, Ian.

2003 "Tourism and sustainability: development and new tourism in the third world". 2ed. Londres; Routledge.

OMT - Organização Mundial do Turismo.

2008 "Sustainable tourism:eliminating poverty". Disponível em: < http://www.unwto.org/step/> Acesso em: 23 Jun. 2009.

Passos, Carlos Roberto Martins; Nogami, Otto.

1998 "Princípios de economia". São Paulo: Pioneira Thimson.

Rabahy, Wilson Abrahão.

2003 "Turismo e desenvolvimento: econômico e estatístico no planejamento". Barueri, SP: Manole.

Ramos, Silvana Pirillo.

2008 "Observatório do turismo: Núcleo de Avaliação, Diagnóstico e Intervenção nas comunidades para o desenvolvimento sustentável do turismo em Municípios do Estado de Alagoas". Disponível em: <http://www.uniethos.org.br/_Uniethos/Documents/ Observat\%C3\%B3rio\%20do\%20Turismo.pdf>. Acesso: 9 jun.. 2008.

Rodrigues, Adyr Balastreri.

2002 “Turismo e desenvolvimento". 3. ed. São Paulo: Huci.

Rodrigues, Adyr Balastreri y Arlete Moyés. 2000. Desenvolvimento sustentável e atividade turística. In: Serrano, C.; Brunhs, H.T.; Luchiari, M. T. D. P. (orgs). "Olhares Contemporâneos sobre o Turismo". Campinas: Papiros.

Ruiz Ballesteros, Esteban; Hernández, Macarena; Coca, Agustín; Cantero, Pedro; \& Del Campo, Alberto.

2008 "Turismo comunitario em Ecuador: comprendiendo el community-based tourism desde la comunidad" , Pasos. Revista de turismo y patrimônio cultural 6(3): 399-418.

Ruiz Ballesteros, Esteban; Hernández- Ramírez, Macarena.

2010 Tourism that empowers? Commodification and appropriation in Ecuador's Turismo Comunitário. Critique of Anthropology 30(2): 201: 229. 
Sampaio, Carlos Alberto Cioce.

2008 "Gestão que privilegia uma outra economia: ecossocioeconomia das organizações. Rio de Janeiro: Qualitymark.

Sen, Amartya Kumar.

2000"Desenvolvimento como liberdade”. São Paulo: Compania das Letras.

Singer, Paul Israel.

1977 "Desenvolvimento e crise". 2ed Rio de Janeiro: Paz e Terra.

Souza, NaIi J.

1999 "Desenvolvimento econômico". 4. ed. São Paulo: Atlas.

Souza Neto, Gerardo Facundo de; Barbosa, Luciana Maciel; Mendes, Eluziane Gonzaga.

2008 "A Modernização do Litoral Cearense e as Comunidades Pesqueiras: O Caso de Tatajuba, CamocimCe". Disponível em: <http://www.sits2008.org.br/ oktiva.net/1893/nota/106773>. Acesso: 29 nov. 2008.

Stronza, Amanda

2001 "Anthropology of tourism: forging new ground for ecotourism and other alternatives" Annual Review of anthropology (30): 261-283.

Tedesco, João Carlos; Campos, Ginez Leopodo Rodrigo.

2001 "Economia solidária e reestruturação produtiva: (sobre) vivências no mundo do trabalho atual”. Passo Fundo. RS: UPF.

Zechner, Talita C. Alves, Flávia K. Sampaio, Carlos Alberto $\mathrm{C}$.

2008 "O papel do turismo no arranjo socioprodutivo de base comunitária da micro-bacia do rio sagrado". Dynamis revista tecno-científica n.14, vol.1, 34-42.

Wallace, Gillian \& Russel, Andrew.

2004 "Eco-cultural tourism as a mean for the sustainable development of culturally marginal and environmentally sensitive regions." Tourism Studies 4 (3): 235: 54 .

Western, David. Definindo o turismo. In: Lindberg, Kreg; Hawkins, Donald E.

1995 "Ecoturismo: um guia para planejamento e gestão".Trad. Leila Cristina de M. Darin. São Paulo: SENAC.

\section{NOTAS}

1. O turismo de massa é aquele que se realiza em destinos populares conhecido, é realizado por grupos definidos pelas operadoras de turismo, onde são predefinidos os horários e lugares a serem visitados para que desta maneira os turistas não entrem em contato parcial ou total com a população residente.
2. A comunidade local referida neste artigo é a localizada no entorno dos centros turistificados.

3. Amarthya Sem, autor do livro desenvolvimento como Liberdade, é um economista Indiano, ganhador do prêmio Nobel de Economia em reconhecimento a sua contribuição a humanidade pela criação IDH, bem como da teoria que está centralizada no desenvolvimento em consequência da liberdade, que nada mais é do que a garantia dos direitos básicos como saúde e educação entre outros para que desta maneira as pessoa se tornem cidadãos e possa fazer suas escolhas de vida.

4. A saber, educação, saúde, moradia, lazer, cultura, direitos políticos entre outros.

5. Gestão democrática e solidária; autogestão; distribuição eqüitativa das riquezas produzidas coletivamente; promoção do desenvolvimento integrado e sustentável; respeito ao ecossistema; valorização do ser humano e do trabalho; no estabelecimento eqüitativo entre homens e mulheres; no empoderamento social.

6. É a diferença entre as despesas e receitas nas contas públicas, quando esta diferença entre os dois é positiva tem-se o superávit primário.

7. Se a poderá dos benefícios sociais como também econômicos.

8. Provocado pela substituição do homem pela maquina nas linhas de produção.

9. Moradores das comunidades locais.

10. Tripé da sustentabilidade são as bases econômicas, sociais e ecológicas.
Recibido:

Reenviado:

Aceptado:

Sometido a evaluación por pares anónimos
$01 / 06 / 10$

$31 / 12 / 10$

$07 / 01 / 11$ 